матча, но и автора единственного гола, а также точное время, на котором этот гол будет забит. После того, как ставка сыграла, болельщик даже не знал о своем выигрыше, поскольку просто забыл про нее, потому что делал ставку в спешке перед отчетом в Грецию. С отпуска производитель мебели возвращался уже миллионером.

В заключении работы стоит отметить, что ставки безусловно зависят не только от удачи, но и от многих факторов, которые уже были перечислены в данной работе. И также важно отметить, что делая ставки нужно быть крайне аккуратным в выборе букмекерской конторы, а также уметь правильно управлять банкроллом. Все остальное придет с опытом.

$$
* * *
$$

1. Александров С.Г. Азартные игры как объект мошенничества // Общество и право. - 2005. - № 3 (9). - С. 140142.

2. Сорокин М.А., Александров С.Г. Международный кубок Конфедераций по футболу - 2017: состояние, перспективы, возможности // Актуальные проблемы современной науки: Материалы V Международной научно-практической конференции молодых ученых, аспирантов, магистрантов и студентов. - Краснодар: ККИ РУК, 2017. - С. 182-183.

3. https://smartgambling.ru/novichkam

4. https://stavki-na-sports.com/articles/

5. https://www.1cupis.ru/info/blog

6. https://probukmeker.ru/post

7. https://bukmekerobzor.info/stati

\title{
Садыралиев Ж. \\ Проблемы применения статистических инструментов при оценке развития муниципальных образований
}

Джалал-Абадский государственный университет имени Б.Осмонова

doi: 10.18411/trnio-09-2021-27

(Кыргызстан, Джалал-Абад)

\section{Аннотация}

На первый взгляд кажется, что с методологической точки зрения вопрос оценки социально-экономического развития органов местного самоуправления (муниципальных структур) не представит много трудностей, проблем. Однако некоторые недостатки в регулировании законодательства в области сочетания управления в органах местного самоуправления в Кыргызстане, особенно в айыл окмоту и городах районного значения, с государственным управлением, требуют особого внимания к организации статистической работы в этих муниципальных структурах, обуславливают рассматривать эти структуры как объекта для специального обзора.

В данной работе предпринята попытка проанализировать некоторые проблемы информационного обеспечения социально-экономического развития данных айыл окмоту и городов районного значения. Автор попытался охарактеризовать процесс сбора (кем) и использование (через кого) муниципальной статистической информации при ведении мониторинга процессов, происходящих в этих муниципальных структурах (MC), при оценке их экономического роста по отраслям, социально-демографического состава населения, уровня их жизни, при определении уровня комплексного обеспечения услугами социальной инфраструктуры. Особенно были отмечены способы коекретного определения и оценки вклада муниципальных образований в социально-экономическое развитие Кыргызской Республики.

Ключевые слова: муниципальные структуры, айыл окмоту, города районного значения, информационные данные, методы организации, оценки сбора статистической информации, система муниципальных индикаторов.

\section{Abstract}

At first glance, it seems that from a methodological point of view, the issue of assessing the socio-economic development of local governments (municipal structures) will not present many 
difficulties and problems. However, some shortcomings in the regulation of legislation in the field of combining management in local self-government bodies in Kyrgyzstan, especially in ayil okmotu and cities of district significance, with public administration, require special attention to the organization of statistical work in these municipal structures, cause these structures to be considered as an object for special review.

In this work, an attempt is made to analyze some of the problems of information support for the socio-economic development of these ayil okmotu and cities of district significance. The author tried to characterize the process of collecting (by whom) and using (through whom) municipal statistical information when monitoring the processes taking place in these municipal structures (MS), when assessing their economic growth by industry, socio-demographic composition of the population, their standard of living, determining the level of integrated provision of social infrastructure services. The methods of specific definition and assessment of the contribution of municipalities to the socio-economic development of the Kyrgyz Republic were especially noted.

Keywords: municipal structures, ayil okmotu, cities of district significance, information data, methods of organization, assessments of the collection of statistical information, a system of municipal indicators.

Введение. Одним из важнейших элементов принятия управленческих решений местного самоуправления о развитии муниципальных образований является своевременное и достаточное предоставление необходимой информации. Основную роль в предоставлении этой информации играет муниципальная статистика, развитие которой является частью государственной статистики и связано с ней рядом сложностей. Подготовка и потребление информации о ситуации в муниципальных образованиях Кыргызской Республики - в айыл окмоту, городах районного значения, селах, резко отличается от данных по республике, областям, районам, городам, так как эта информация формируется и изготовляется в зависимости от особенностей, высоты уровня задач, решаемых в рамках создания и реализации государственной политики на местах.

В сфере управления на практике при оценке места, роли и структуры используемых информационных ресурсов необходимо учитывать специфику административнотерриториальных структур, особенно муниципальных образований, на которых формируется эта информация. Чтобы обеспечить развитие малых муниципальных образований в городах районного масштаба, районах и айыл окмоту, необходимо иметь информацию в различных характеризующих их направлениях, без которой невозможно узнать о проблемах и ситуации в них.

Осуществление проводимых реформ, изменения в органах местного самоуправления, являющихся основой Кыргызской Республики по повышению уровня жизни населения, требует постоянного совершенствования системы статистических показателей, которые их отражают, и ставит целью отражать каждого из этих изменений индикаторами социальноэкономического развития.

В данной статье сделана попытка дать характеристику текущему состоянию муниципальной статистики, ее достижениям, недостаткам и проблемам, требующим решения при диагностике процессов, происходящих в муниципальных структурах с использованием в качестве инструментария статистических показателей.

Значение муниципальной статистики в практике государственного управления.

Одна из основных характеристик эпохи глобализации - неравенство в развитии стран по всему миру, результатом которого является сохранение неравенства в уровне жизни населения. При ближайшем рассмотрении видно, что это связано с процессами развития в органах местного самоуправления и муниципальных структурах, и что к этим процессам нужно подходить очень глубоко и внимательно. В Кыргызстане, в ответ на этот вопрос, были сформированы нижние уровни административно-территориальной системы, айыл окмоту как исполнительные органы айылных аймаков, городские мэрии районного значения, айыл башчы сел, которые были вовлечены в государственное планирование, в создании стратегии 
социально-экономического развития, намечены пути их взаимодействия с высшими государственными органами. Создана иерархия государственной власти сверху-вниз [1]. Это привело к необходимости диагностики различных состояний и обозначению роли развития в органах местного самоуправления (нижние уровни), и, как показала жизнь, посредством этого путем определения остроты их проблем, сложности решения вопросов, их необходимости при принятии управленческих решений.

Эти изменения подчеркивают необходимости актуализации интереса к статистическим показателям, позволяющим анализировать процесс социальноэкономического роста муниципальных структур при изучении проблем глобальной экономической и социальной политики [2], в то же время это означает, что необходимо разработать способы исследования теоретико-методологических путей разработки государственного регулирования и применения, эффективных мер.

Целесообразно обеспечить системой показателей для улучшения информационной базы муниципальных образований, ведения мониторинга органами управления по изменениям, происходящим в муниципальных структурах, определить следующие шаги по развитию муниципальной статистики, необходимой при разработке муниципальных программ:

- разработка методологического-теоретического справочника по определению социально-экономических процессов в муниципальных структурах (MC) или вне их, но оказывающих влияние на их изменения;

- уточнение методик оценки состояния МС и некоторых признаков, характеризующих социально-экономическое развитие;

- создание системы статистических показателей, определяющих изменения, происходящих в МС, уточнение индикаторов;

- обеспечение МС материалами для анализа или их наличие.

Несмотря на то, что за последнее десятилетие было сделано многое для формирования и развития муниципальной статистики, улучшения инструментов для расчета процессов и явлений на нижних уровнях административно-территориальных единиц и их использования в аналитическом направлении, научных исследованиях, практическом управлении, многое еще предстоит выполнять [3].

Рассмотрим состояние дел в Российской Федерации, многие статистические методики которой Кыргызстан применяет в соответствии со своими условиями. У них принято Постановление Правительства РФ «О развитии системы муниципальной статистики» от 29.10 .1995 года за № 1044 [4]. Госкомстатом России был разработан и утвержден "Примерный перечень статистических показателей социально-экономического положения муниципальных образований”, а затем, в 1997 г. была утверждена "Унифицированная система показателей, характеризующих социально-экономическое положение муниципального образования". Постоянно происходящее совершенствование этой базы данных, увеличение числа включенных в неё показателей дополняется шагами по обеспечению её доступности для всех видов пользователей [5].

С 2008 г. БД ПМО на федеральном уровне дополнена системой показателей эффективности деятельности органов управления городских округов и муниципальных районов. Представленные в ней данные призваны обеспечить оценку положения дел в следующих сферах: экономическое развитие, дошкольное, общее и дополнительное образование, культура, физическая культура и спорт, жилищное строительство и обеспечение граждан жильём, жилищно-коммунальное хозяйство и организация муниципального управления [6].

В муниципальных структурах Кыргызстана эти показатели также не собираются, не разработан механизм их сбора, в айыл окмоту разработан только механизм сбора статистических данных по сельскому хозяйству, остальные требуют глубокого исследования. 
Поэтому считаем, что созрела необходимость и в условиях Кыргызстана рассчитывать показатели социально-экономического развития муниципального сектора на уровне страны, т.е. необходимо знать долю органов местного самоуправления в экономике республики в целом, и если мы хотим использовать рычаги управления в соответствии с этим, нам также необходимо формировать муниципальную статистику, без которой мы не можем определить место и роль самоуправления, являющегося основой демократии, в экономике, невозможно довести народное управление до логического конца.

В Кыргызской Республике существует всего один закон, регулирующий статистическую работу, который называется «Об официальной статистике» и был принят 8 июля 2019 года. Глава 2, статья 6 этого закона гласит, что система Национальной статистики состоит из следующих ведущих официальной статистики:

1) Национальный статистический комитет;

2) другие структурные подразделения, ведущие официальную статистику [1].

На наш взгляд, в этом законе не ведется речь о статистике муниципальных образований или муниципальной статистике, не выделен как какой-то отдельный вид статистики. Однако, раз существуют органы местного самоуправления, то наличие в статистике Кыргызской Республики отдела муниципальной статистики, остается требованием времени. В Кыргызстане 1/3 населения проживает в городской местности, 2/3 в сельской местности, 31 городов, 9 поселков городского типа, 3 поселка, 452 сельских округа включены в органы местного самоуправления страны [7].

Наличие муниципальной статистики обеспечивает наличие своих показателей в каждой из вышеперечисленных муниципальных образований, их информационное обеспечение. Муниципальные структуры разного уровня управления, обеспеченные необходимой информацией, получат возможность создавать свои собственные программы развития.

В особенности, комплексное исследование социально-экономического развития муниципальных образований играет важную роль при разработке государственных программ развития. Если взять за основу комплексно исследованные и достигнутые показатели каждого айылного аймака, городов районного значения и разработать программу айылного аймака, района, а затем области, республики, то такая программа будет обоснованной. Однако из-за неточности и отсутствия статистических показателей по основным отраслям айылных аймаков (айыл окмоту), являющихся основной движущей силой, программы развития спускаются от верхних уровней власти к нижним, а не наоборот, в результате чего прогнозные значения развития рассчитываются до уровня районов, они не конкретизируются и не доходят до уровней айыльных аймаков.

В Кыргызстане действующим нормативным документом на сегодняшний день считается План социально-экономического развития органов местного самоуправления (ПСЭР). Одним из ключевых элементов этого плана является создание системы мониторинга и оценки выполнения закрепленных функций и услуг местными сообществами, государственными и местными органами власти [8], однако не предусматривает мониторинга по статистическим показателям.

Наличие таких проблем требует от Национального статистического комитета Кыргызской Республики создания системы муниципальных показателей, которые будут включены в годовую республиканскую статистическую программу и которые позволили бы осуществлять мониторинг на уровне муниципальных структур. Сегодня вопрос расчета и оценки социально-экономического развития органов местного самоуправления является одним из наименее изученных направлений экономической науки в Кыргызстане, изучение которого остро стоит на повестке дня.

В большинстве случаев основой многих исследований, связанных с анализом текущего состояния социально-экономического развития муниципальных образований в Кыргызстане, являются данные официальной государственной статистики, которые могут быть добавлены, собраны и поддержаны из разных мест, отсутствует целостная система. 


\section{Проблемы применения статистических данных при социально-экономической оценке муниципальных структур.}

Обзор статистических инструментов, используемых в научном исследовании муниципальной структуры, показывает необходимость расширения и углубления подхода к применяемым в настоящее время муниципальным показателям, что создают условия для диагностики и определять пути развития в научных исследованиях муниципальных структур. Однако недостаточное количество исследований по развитию МС в экономической науке подчеркивает необходимость ведения научной работы в этом направлении.

Анализ текущей ситуации в муниципальных структурах с использованием статистических показателей в качестве показателей, характеризующих данную ситуацию, показывает, что существует ряд сложных и трудных проблем в уточнении показателей, и они зависят от ряда условий.

Во-первых, специфика этих объектов исследования, небольшие размеры некоторых нижестоящих административно-территориальных единиц, отсутствие сетей, полностью отражающих их статистические показатели, не позволяют собирать статистические показатели полностью. Например, статистический учет ведется в городах областного уровня, а в айыльных аймаках, в городах районного масштаба количество населения достигает от 3 тысяч до 40 тысяч, в крупных айыльных аймаках развиты все производственные и социальные секторы, в мелких - единичные, таких всего несколько. В таких случаях как можно сравнивать уровень развития айыльных аймаков, то есть, как можно оценить «плохохорошо», «хорошо развито, слабо развито».

Потенциал базы данных муниципальной статистики также ограничиваются установленной законом конфиденциальностью первых числовых данных, полученных от респондентов. В результате публикациям предоставляется только обобщенная информация, информация по отдельным хозяйствующим субъектам не предоставляется, что зарождает трудность при планировании их мощности.

Филиалы некоторых компаний работают в айыл окмоту, но бухгалтерия находится в центре, так как мы можем соотнести объем производства этого предприятия с объемом муниципальной структуры. Должна существовать политика, согласно которой по закону отчеты должны подаваться по месту работы. В Кыргызстане показатели айыл окмоту, такие как промышленность и розничная торговля, рассчитывается НСК соотношением по айыл окмоту в конце года, но оперативность и доступность этих показателей вызывают сомнения.

Наличие единого экономиста-статиста в штатном расписании айыл окмоту и городов, ведущего статистический учет, нерешенность в полноценном виде того, как и в каких сферах, он ведет статистический учет, а также большой объем работы в некоторых крупных айыл окмоту препятствуют сбору показателей, необходимых для исследования. Рассмотрим это подробнее.

В целях реализации Закона Кыргызской Республики «О порядке делегирования отдельных государственных полномочий органам местного самоуправления», Руководствуясь Постановлением Правительства Кыргызской Республики от 19.12.2014 № 715, между главами айыльных аймаков, мэрами городов и зав. отделами районных и городских статистических отделов были подписаны соглашения о наделении органов местного самоуправления отдельными государственными полномочиями по сбору статистических данных [9].

В соответствии с этим соглашением статистические работы в сельской местности и городах районного значения будут проводиться экономистом-статистиком в соответствии с условиями соглашения. Если мы рассмотрим и проанализируем эти договора, то заметим, что экономист-статистик в основном занимается только сельскохозяйственными работами на своем участке. Тогда возникает закономерный вопрос, кто будет работать по другим отраслям айыльного аймака, кто должен вести статистический учет. В результате надо решить вопрос о том, кто, работая в тесной связи с районной статистикой, будет вести 
полную муниципальную статистику каждого органа местного самоуправления по таким вопросам, как розничная торговля, услуги, промышленность, предпринимательство, инвестиции, строительство, транспорт, пассажирский транспорт, здравоохранение, выявление бедности, миграция, перепись населения. Когда этот вопрос будет решен, тогда мы и сможем определить долю муниципального сектора во всех отраслях по всему Кыргызстану.

В айыльных аймаках с населением от 20000 до 40000 человек, по количеству населения превышающий отдельных районов, отсутствует методика и механизм определения уровня качества жизни населения, средней заработной платы, а уровень бедности даже на районном уровне не определяется. Методика определения бедности в масштабах НСК не оперативно, результат выйдет через год, практического значения не имеет. Как оценить работу глав айыльных аймаков по улучшению качества жизни населения? Айыл окмоту самостоятельно определяют уровень бедности через Министерство социальных дел и труда, в то время как Организация Объединенных Наций для определения развития стран использует данные НСК КР. Если существовала бы муниципальная статистика, вопрос по благосостоянию населения можно было бы рассчитать по единой системе показателей.

По методологии, используемой в статистике, вопрос расчета производства услуг, розничной торговли, промышленности, с применением дорасчетов продукций, произведенных в личных приусадебных участках, подсобных хозяйствах (объем рассчитывается самими статистами) определяется на региональном (областном, районном) уровне, а на муниципальном уровне не определяются. В результате место муниципального сектора в экономике страны, его доля в ВВП остается неопределенной, что требует независимого статистического учета всех муниципальных образований в республике [10].

Органы местного самоуправления сами должны решить, проводить ли эту статистическую работу в соответствии со штатным расписанием одному человеку или группой специалистов, а НСК должен оказать методологическую и инструментальную помощь.

\section{Вместо заключения}

На первый взгляд муниципальный статистический учет кажется очень сложным, поскольку многочисленные показатели, применяемые в стране в целом и в регионах, создают трудности в их применении в муниципальных структурах из-за небольшого количества показателей, используемых в них, а также компетентности специалистов, осуществляющих их сбор. Специальный методический совет должен отсортировать эти показатели, отобрать необходимые и добавить в муниципальную статистику.

Поэтому, будет правильным только тогда, когда Правительство Кыргызской Республики примет постановление о развитии муниципальной статистики, разработает и утвердит приложение «Статистические показатели социально-экономического развития органов местного самоуправления», вводит порядок сбора таких данных, а также если статистические данные республики в законном порядке будут разделены на статистические показатели госсектора и муниципального сектора. Обеспечение «административной, финансовой, экономической и политической независимости органов местного самоуправления», как указано в пятом абзаце пункта 2 Программы развития местного самоуправления на 2018-2023 годы [9], невозможно без муниципальной статистики.

Без формирования муниципальной статистики мысль, изложенная в 7 абзаце пункта 2 Программы развития местного самоуправления на 2018-2023 гг. [10] в виде «внедрения системы оценки деятельности органов местного самоуправления, повышают эффективность и потенциал органов местного самоуправления», не будет выполнена до тех пор, пока муниципальные структуры не будут оценены по статистическим показателям.

При формировании муниципальной статистики особое внимание следует уделять использованию исследований ученых, зарубежного практического опыта, придется 
постепенно согласоваться с тенденцией развития муниципальной статистики, составления на всех уровнях.

1. Современное состояние местного самоуправления в Кыргызской Республике: административные возможности и вызовы в развитии местных сообществ: Муниципалитет №6 (116) //www.municipalitet.kg

2. Минакир П.А., Демьяненко А.Н. Пространственная экономика: эволюция подходов и методология // Пространственная экономика. 2010. № 2. С. 6-32.

3. Дьяченко В.Н. Проблемы использования статистической информации при разработке целевых программ социально-экономического развития Дальнего Востока // Вопросы статистики. 2009. №1. С. 69-78

4. Дьяченко В.Н. Проблемы использования статистического инструментария при оценке развития муниципальных образований // Региональная экономика и управление:электронный научный журнал, 2018. № 4 (56)

5. Сидоров А.А., Силич М.П. Методические подходы к оценке социально-экономического развития муниципальных образований // Известия Томского политехнического университета. № 6. 2008. Т.313. С. 5562.

6. Леонов С.Н. Становление муниципальной статистики, ее современное состояние и соответствие потребностям исследований региональной экономики // Вестник Томского государственного университета. 2015. № 400. C. 223-231.

7. Закон КР “Об официальной статистике” г. Бишкек, от 8 июля,1919 года №82

8. Статистическая программа на 2021 год.

9. Программа местного самоуправления Кыргызской Республики на 2018-2023 годы.

10. НСК. Кыргызстан в цифрах /Статистический сборник -2019. -С.40-41.

\section{Саитов В.В., Кузьменко О.В. \\ К вопросу стратегического управления устойчивым развитием предприятия}

Азово-Черноморский инженерный институт ФГБОУ ВО Донской ГАУ

doi: 10.18411/trnio-09-2021-28

(Россия, Зерноград)

\section{Аннотация}

В статье представлены теоретические аспекты к раскрытию категорий «стратегия» и «устойчивость» в концепции стратегического управления устойчивым развитием организации. Отмечены отличительные особенности стратегии как инструмента управления деятельностью предприятия. Представлена классификация факторов экономической устойчивости применительно к сельскохозяйственной отрасли.

Ключев
устойчивость.

\section{Abstract}

The article presents theoretical aspects to the disclosure of the categories «strategy» and «sustainability» in the concept of strategic management of sustainable development of an organization. The distinctive features of the strategy as a tool for managing the activities of an enterprise are noted. The classification of factors of economic sustainability in relation to the agricultural sector is presented.

Keywords: strategy, strategic management, economic sustainability.

Практика деятельности отечественных и зарубежных предприятий показала, что в условиях процессов глобализации обостряются проблемы развития конкуренции на рынках всех уровней в условиях нестабильности и рисков внешней среды, что, в свою очередь, влияет на внутреннюю среду предприятий и состояние их стратегического потенциала. Это вызывает необходимость в разработке новых механизмов ведения бизнеса, новых методов управления, что нашло свое отражение в концепции устойчивого развития предприятия.

В то же время практика показала, что крайне редко существующая на предприятии стратегия способна обеспечить их устойчивое развитие. Причина этого состоит в том, что 